\title{
Capillary Leak Syndrome Following Snakebite Envenomation
}

\author{
V. Udayabhaskaran, E. T. Arun Thomas ${ }^{1}$, Bhagya Shaji² \\ Department of Internal Medicine, Malabar Medical College, Kozhikode, Departments of ${ }^{1}$ Nephrology and ${ }^{2}$ Neurology, Government Medical College, \\ Thiruvananthapuram, Kerala, India
}

\section{Abstract}

Capillary leak syndrome is a unique complication that follows Russell's viper envenomation. This syndrome has a very high fatality rate and is characterized by parotid swelling, chemosis, periorbital edema, hypotension, albuminuria, hypoalbuminemia, and hemoconcentration. This syndrome is frequently recognized from the southern parts of India, especially from the state of Kerala. It has been postulated that a vascular apoptosis inducing component of Russell's viper venom that is not neutralized by the commercially available anti-snake venom (ASV) is responsible for this complication as it occurs even after adequate doses of ASV administration in most cases. Acute kidney injury often requiring dialysis is invariably present in all patients because of reduced renal perfusion and ischemic acute tubular necrosis as a result of hypotension. Management mainly involves aggressive fluid resuscitation to maintain adequate tissue perfusion. There are no other proven effective treatment modalities, except a few reports of successful treatment with plasmapheresis. Methylprednisolone pulse therapy, terbutaline, aminophylline, and intravenous immunoglobulin are other treatment modalities tried.

Keywords: Capillary leak syndrome, envenomation, Russell's viper, Snakebite

\section{INTRODUCTION}

Snakebite is a common medical emergency and an occupational hazard, more so in tropical India, where farming is a major source of employment. In India, approximately 81,000 cases of snakebite envenomation occur each year, which result in about 11,000 deaths. ${ }^{[1]}$ These numbers may be a gross underestimation of the true morbidity and mortality as a significant number of patients are still managed by traditional healers. Capillary leak syndrome (CLS) is a unique complication that occurs with Russell's viper envenomation, with a very high mortality rate, $58 \%$ in the largest available series. ${ }^{[2]}$ This under-recognized complication is characterized externally by parotid swelling, conjunctival chemosis, and periorbital edema coupled with hypotension, albuminuria, hypoalbuminemia, and hemoconcentration. This complication can occur even among those victims of snakebite who present early to medical facilities and receive adequate quantities of anti-snake venom (ASV). Clinical features, diagnostic criteria, and management protocol of this dangerous complication are not yet clearly described in medical literature.

\begin{tabular}{|l|l|}
\hline \multicolumn{2}{|c|}{ Access this article online } \\
\hline Quick Response Code: & Website: \\
\hline & www.ijccm.org \\
\cline { 2 - 2 } & \\
\hline
\end{tabular}

\section{EPIDEMIOLOGY}

Even though CLS is a well-recognized complication of viper bite, published data are scarce. In recent times, this syndrome is increasingly being reported from pockets in South India, particularly North Kerala and Pondicherry in Tamil Nadu, presumably because of unique venom characteristics of the snake in this region. Some studies from Kerala show that CLS is a major cause of mortality in patients with viper bite who were managed with adequate doses of ASV. In one study from North Kerala, CLS contributed to majority (23 of 28) of deaths. ${ }^{[2]}$

\section{Pathogenesis}

The pathogenesis of CLS is not fully elucidated. Some protein components of the viper venom are thought to cause systemic vascular endothelial damage. Vascular permeability increases as a result of endothelial damage, leading to

Address for correspondence: Dr. E. T. Arun Thomas, Department of Nephrology, Government Medical College, Thiruvananthapuram - 695 011, Kerala, India. E-mail: dretarunthomas@gmail.com

This is an open access article distributed under the terms of the Creative Commons Attribution-NonCommercial-ShareAlike 3.0 License, which allows others to remix, tweak, and build upon the work non-commercially, as long as the author is credited and the new creations are licensed under the identical terms.

For reprints contact: reprints@medknow.com

How to cite this article: Udayabhaskaran V, Arun Thomas ET, Shaji B. Capillary leak syndrome following snakebite envenomation. Indian J Crit Care Med 2017;21:698-702. 
leakage of plasma to interstitial space and edema formation, hypoalbuminemia, and intravascular volume depletion. Two vascular apoptosis-inducing proteins (VAPs) from snake venom which are members of the metalloproteinase/disintegrin family have already been described. VAP1 is a basic, homodimeric protein with a molecular mass of $110 \mathrm{kDa}$, and VAP2 is an acidic, monomeric protein with a molecular mass of $55 \mathrm{kDa} \cdot{ }^{[3]}$ VAP2 has been shown to kill vascular endothelial cells in culture, and the death of cells exhibited the characteristic features of apoptosis. The apoptotic activity of VAP2 seemed to be specific to endothelial cells. ${ }^{[3]} \mathrm{A} 110 \mathrm{kDa}$ enzyme called L-amino acid oxidase is another apoptosis-inducing factor isolated from hemorrhagic snake venom. ${ }^{[4,5]}$

Another postulated mechanism for increased capillary permeability is cytokine activation by the venom. Various studies have showed augmented levels of cytokines and other pro-inflammatory substances in sera of snakebite victims as well as in experimental animals injected with snake venom. ${ }^{[6-8]}$ These result in the activation of endothelial cells and leukocytes, leading to the expression of cell surface adhesion molecules ultimately causing increased vascular permeability. ${ }^{[9]}$ Snake venom is rich in phospholipase A2 (PLA2). The lysophosphatidylcholine generated by PLA2 is considered as a potent inflammatory agent that can modulate the intensity of reactive oxygen species production at the site of inflammation..$^{[9-11]}$ Pathways involved in the pathogenesis of snake venom-induced CLS are represented schematically in Figure 1.

Theoretically, this complication should not occur if adequate quantity of ASV is administered early after the bite, as ASV

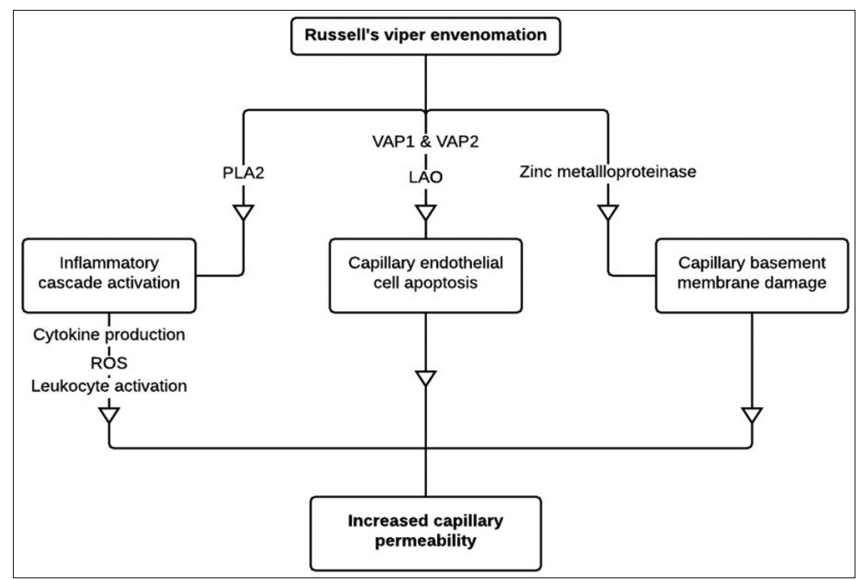

Figure 1: Possible pathogenesis of snake venom-induced capillary leak syndrome. PLA2 of the Russell's viper venom is one of the main components that triggers the inflammatory cascade resulting in cytokine production, formation of ROS, and leukocyte activation. VAP1, VAP2, and LAO present in the venom induce vascular endothelial apoptosis. Zinc metalloproteinase present in the venom can cause direct damage to capillary basement membrane. The outcome of this entire pathway is increased capillary permeability resulting in various manifestations of capillary leak syndrome. PLA2: Phospholipase A2; ROS: Reactive oxygen species; VAP1: Vascular apoptosis-inducing protein 1; VAP2: Vascular apoptosis-inducing protein 2; LAO: L-amino acid oxidase supposedly neutralizes all components of the venom. But most of the times, CLS occurs even after adequate doses of ASV administration. ${ }^{[12]}$ The lack of neutralization of lethal constituents of Russell's viper venom responsible for this syndrome by the currently available ASV questions its efficacy. The venom obtained from a single source, the Madras Crocodile Bank situated in the state of Tamil Nadu is being used for manufacturing ASV supplied all over India and Sri Lanka. ${ }^{[13]}$ As there is geographical variation of Indian Russell's viper venom composition, ${ }^{[14]}$ it is highly likely that the currently used antivenom is inadequate to fully neutralize all the components of the venom and prevent all the complications across the different regions of the Indian subcontinent.

\section{Clinical Features}

CLS is observed to occur only after Russell's viper envenomation in South India. In most cases, the species of the biting snake cannot be identified, but the syndromic approach can readily identify Russell's viper envenomation. Typically, victims have a local reaction at the bite site of varying severity, incoagulable blood, acute kidney injury (AKI), and infrequently, neurological manifestations in the form of ptosis and diplopia. ${ }^{[15]}$ Severe neurological manifestations are usually rare. The full-blown features of CLS usually appear only by the $2^{\text {nd }}$ or $3^{\text {rd }}$ day, but parotid swelling, chemosis, periorbital edema, and proteinuria can appear as early as 12-24 $\mathrm{h}$ after the bite. ${ }^{[16]}$ The characteristic finding is significant edema in periorbital and parotid regions because these areas have loose subcutaneous tissue, and gravitational pooling occurs in supine position. As the edema in these regions increases, it results in a peculiar appearance of the head, best described as the "viper head appearance" [Figure 2]. Fluid accumulation can also occur in other regions in the form of pleural effusion, ascites, and generalized edema. As a result of intravascular volume depletion, hypotension and

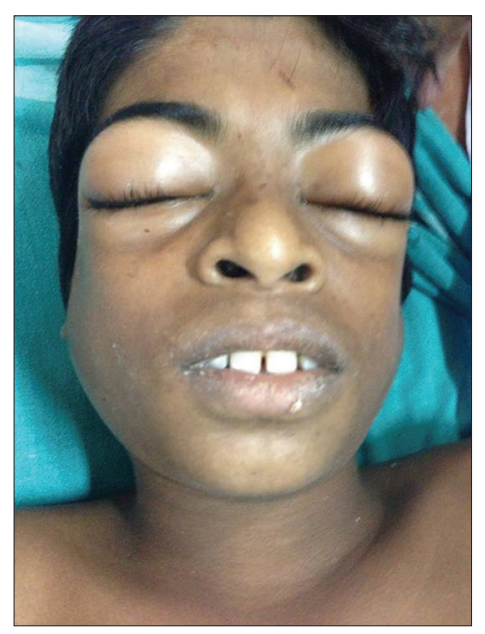

Figure 2: Photograph of a patient with capillary leak syndrome following Russell's viper envenomation showing the characteristic appearance of the head due to parotid swelling and periorbital edema 
shock ensues. Laboratory testing usually reveals increasing hematocrit because of hemoconcentration, but many a times, this is not evident because of coexisting hemolytic anemia due to direct damage to the red cell membrane by the venom and microangiopathic hemolysis as a result of disseminated intravascular coagulation (DIC). Hypoalbuminemia occurs invariably in all cases. Urine examination reveals proteinuria indicating increased capillary permeability. Central venous pressure (CVP) will be usually very low, approaching zero most of the times.

The most common complication of CLS is AKI. ${ }^{[16]}$ Most of the times, there is variable degree of kidney injury before this syndrome sets in, due to direct effect of the venom and other factors such as dehydration, hypotension, DIC, rhabdomyolysis, hemoglobinuria, and thrombotic thrombocytopenic purpura. The severity of this initial renal insult is accentuated by the CLS, in part due to reduced renal perfusion and due to ischemic acute tubular necrosis as a result of hypotension. Leakage of plasma from pulmonary capillaries can lead to impaired gas exchange. Acute angle-closure glaucoma is a frequent ophthalmological complication. Ciliary body edema resulting in anterior rotation of ciliary processes and anterior displacement of lens-iris diaphragm seems to be the most probable explanation for angle closure. ${ }^{[17-19]}$ If the hemodynamic status of the patient does not improve in 1 to 2 days, severe multiorgan dysfunction and death ensue.

\section{Diagnosis}

There are no accepted diagnostic criteria. We suggest the criteria used by Thomas and Kumar with some modifications. ${ }^{[16]}$ Diagnosis is made in the presence of bilateral parotid swelling, chemosis, and periorbital edema following snakebite along with any three or more of the following:

- Systolic blood pressure $<90 \mathrm{mmHg}$ or fall in the mean arterial pressure by $20 \mathrm{mmHg}$

- Hematocrit $>45 \%$ or $>20 \%$ elevation from the baseline

- $\quad$ Proteinuria defined by protein-creatinine ratio $>1$

- $\quad$ Serum albumin $<3 \mathrm{~g} / \mathrm{dl}$

- Sonological evidence of the third-space fluid collection.

Many patients following Russell's viper envenomation develop lesser degrees of periorbital puffiness and parotid edema than seen in typical CLS, without hypotension, which usually resolves in 2-3 days. This may be considered as a milder form of CLS not fulfilling all the necessary criteria of CLS.

\section{TREATMENT}

\section{Stabilization}

All patients require intensive care support. The priority is stabilization of airway and breathing. Supplemental oxygen should be supplied to all patients, and oxygenation should be monitored continuously with pulse oximetry. Intubation and mechanical ventilation may be required to support an increased work of breathing if present.

\section{Anti-snake venom}

Most patients would have already received adequate doses of polyvalent ASV before this syndrome sets in. ${ }^{[12]}$ This clearly shows inadequacy of present ASV available in India in preventing this complication. There are no data to support additional doses of ASV when features of capillary leak appear. ASV should be promptly administered if not given already.

\section{Monitoring the patients}

Volume status, blood pressure, tissue perfusion, and the presence or absence of pulmonary edema must be assessed before and after each infusion bolus of crystalloids and throughout the illness. The fact that hypoperfusion can occur even in the absence of hypotension should always be kept in mind. Signs of hypovolemia and hypoperfusion include tachycardia, cool and clammy skin, restlessness or obtundation, oliguria or anuria, and lactic acidosis. Although not essential, most patients often require a central venous catheter (CVC) for drug and fluid administration, infusion of blood products, and to draw blood. If CVC is in place, it can also be used to monitor central venous oxyhemoglobin saturation $\left(\mathrm{S}_{\mathrm{cv}} \mathrm{O}_{2}\right)$ and CVP. Even though routinely practiced, it is unclear whether targeting hemodynamic parameters used to treat shock, i.e., $\mathrm{S}_{\mathrm{cv}} \mathrm{O}_{2} \geq 70 \%$, CVP 8-12 mmHg, a mean arterial pressure $\geq 65 \mathrm{mmHg}$, and a urine output $\geq 0.5 \mathrm{~mL} / \mathrm{kg}$ per hour are helpful in the treatment of CLS. ${ }^{[20-22]}$ Additional parameters that are frequently monitored include blood urea, serum creatinine, hemoglobin, hematocrit, platelet count, serum albumin, and serum lactate.

\section{Restore perfusion}

Measures to restore perfusion include sequential infusion of intravenous (IV) fluids and if needed, vasopressors and inotropic medications. Crystalloids are the preferred fluids as colloids have not convincingly been shown to be superior in these patients. Colloids are costly and their effectiveness is greatly reduced because proteins with a molecular weight $\leq 200 \mathrm{kDa}$ (e.g., albumin) leak from the intravascular to the interstitial space. ${ }^{[23]}$ Fresh frozen plasma (FFP) may be used only when there is coexisting coagulopathy. The use of crystalloids should not be delayed while awaiting FFP because hypotension and intravascular volume depletion if not corrected early can lead to severe kidney injury with oliguria or anuria. Hetastarch solutions have been associated with bad outcome in patients with hypovolemic and septic shock, and therefore, it is reasonable to avoid their administration in CLS. ${ }^{[24,25]}$ Hyperkalemia which is frequently seen in these patients because of AKI and muscle damage limits the use of potassium-containing fluids such as Ringer's lactate, making normal saline the preferred crystalloid. If CLS progresses to shock and severe oliguric AKI, the management becomes all the more challenging because of the resultant fluid overload state precluding further IV hydration. Such patients also do not tolerate intermittent hemodialysis necessitating continuous renal replacement therapy (CRRT) further adding to the expense of the treatment. Fluid therapy is more challenging 
in patients with associated noncardiogenic pulmonary edema because IV fluids can further worsen the pulmonary functions. We recommend administering fluids as sequential small boluses (e.g., $200 \mathrm{ml}$ ) with chest auscultation after each bolus and monitoring pulse oximetry. CVP should be monitored in these patients as it is often difficult to clinically distinguish between pulmonary capillary leak and fluid overload as a result of oliguric AKI.

IV fluids should be given as long as they increase perfusion without seriously impairing gas exchange. IV vasopressors are useful in patients who remain hypotensive despite adequate fluid resuscitation or who develop pulmonary edema precluding further fluid administration. There is no definite evidence of the superiority of one vasopressor over another for CLS. We prefer norepinephrine by extrapolating the evidence from septic shock although dopamine can also be reasonably used. ${ }^{[26-28]}$

\section{Renal replacement therapy}

AKI is another challenge in the management of these patients. Indications for initiating urgent dialysis are severe fluid overload, hyperkalemia (plasma potassium concentration $>6.5 \mathrm{mEq} / \mathrm{L}$ ) or rapidly rising potassium level, signs of uremia, such as pericarditis, encephalopathy, or an otherwise unexplained decline of mental status and severe metabolic acidosis $(\mathrm{pH}<7.1)$. It would be better to electively initiate dialysis before the development of severe electrolyte disturbances and fluid overload if despite optimal medical management, the patient shows no signs of improvement in renal function. There are two major challenges in prescribing RRT in this condition. Hemodynamic instability is the first challenge. Most patients do not tolerate intermittent hemodialysis, thus necessitating the need for CRRT. The second challenge is deciding the ultrafiltration rate and volume. Patients with CLS are frequently edematous but have intravascular volume depletion due to hypoalbuminemia and increased capillary permeability. We suggest that ultrafiltration rate and volume during RRT to be decided depending on CVP, which is a more reliable measure of intravascular volume. The same internal jugular venous dialysis catheter may be used to measure the CVP before the start of hemodialysis. CVP can also be measured using femoral catheter with the measurement made with the headboard positioned at zero degree..$^{[29,30]}$ Inferior vena cava size and collapsibility index on ultrasonography is another method to determine the intravascular volume. ${ }^{[31,32]}$

\section{Therapy with unproven benefits}

There are a few case reports claiming successful management of CLS with plasmapheresis. ${ }^{[33,34]}$ The postulated mechanism of action of plasmapheresis is the removal of the components of venom responsible for capillary damage that are not effectively neutralized by the antivenom. Plasmapheresis can also, to some extent, remove the cytokines and other inflammatory mediators implicated in the pathogenesis of capillary damage. Authors of this article do not recommend plasmapheresis as none of these studies had a control group, and the inclusion criteria of the study population were not well defined. As coagulopathy and hypotension are the two important limiting factors for initiating plasmapheresis, it is likely that the patients who underwent the intervention in these reports had less severe disease. This could be the reason for better survival seen after plasmapheresis. Controlled studies with comparable baseline characteristics between the two groups are needed to define the exact role of plasmapheresis.

Many physicians practice giving pulse methylprednisolone in the view that it is a cytokine-mediated event. ${ }^{[16]}$ Till date, there are no available data regarding the effectiveness of this intervention. Terbutaline, aminophylline, and IV immunoglobulin are other treatment modalities tried as these are found to be useful in idiopathic CLS. ${ }^{[35-37]}$

\section{Prognosis}

The prognosis available from the literature is variable mainly because of the lack of uniform definition of this syndrome, with mortality rate ranging from $43 \%$ to $67 \%{ }^{[2,12,16,17,38]}$ In the author's experience, full-blown CLS with hypotension persisting even after adequate fluid resuscitation has near $100 \%$ mortality.

\section{Conclusion}

CLS is an under-recognized but deadly complication that can follow Russell's viper envenomation. Most of the reports on this syndrome are from South India presumably because of different venom characteristics of the snake. Till now, there are no definite diagnostic criteria or accepted management protocols.

\section{Declaration of patient consent}

The authors certify that they have obtained all appropriate patient consent forms. In the form, the patient has given his consent for his images and other clinical information to be reported in the journal. The patient understand that name and initials will not be published and due efforts will be made to conceal identity, but anonymity cannot be guaranteed.

\section{Financial support and sponsorship}

Nil.

\section{Conflicts of interest}

There are no conflicts of interest.

\section{References}

1. Kasturiratne A, Wickremasinghe AR, de Silva N, Gunawardena NK, Pathmeswaran A, Premaratna R, et al. The global burden of snakebite: A literature analysis and modelling based on regional estimates of envenoming and deaths. PLoS Med 2008;5:e218.

2. Krishnadas T, Sasidharan PK. Snake bites in North Kerala, demographic profile and measures for prevention. J Evol Med Dent Sci 2014;3:990-8.

3. Masuda S, Hayashi H, Araki S. Two vascular apoptosis-inducing proteins from snake venom are members of the metalloprotease/ disintegrin family. Eur J Biochem 1998;253:36-41.

4. Suhr SM, Kim DS. Identification of the snake venom substance that induces apoptosis. Biochem Biophys Res Commun 1996;224:134-9. 
5. Torii S, Yamane $\mathrm{K}$, Mashima $\mathrm{T}$, Haga N, Yamamoto K, Fox JW, et al. Molecular cloning and functional analysis of apoxin I, a snake venom-derived apoptosis-inducing factor with $\mathrm{L}$-amino acid oxidase activity. Biochemistry 2000;39:3197-205.

6. Zamuner SR, Zuliani JP, Fernandes CM, Gutiérrez JM, de Fátima Pereira Teixeira C. Inflammation induced by Bothrops asper venom: Release of proinflammatory cytokines and eicosanoids, and role of adhesion molecules in leukocyte infiltration. Toxicon 2005;46:806-13.

7. Petricevich VL, Teixeira CF, Tambourgi DV, Gutiérrez JM. Increments in serum cytokine and nitric oxide levels in mice injected with Bothrops asper and Bothrops jararaca snake venoms. Toxicon 2000;38:1253-66.

8. Moreira V, Zamuner SR, Wallace JL, Teixeira Cde F. Bothrops jararaca and Crotalus durissus terrificus venoms elicit distinct responses regarding to production of prostaglandins E2 and D2, and expression of cyclooxygenases. Toxicon 2007;49:615-24.

9. Zuliani JP, Fernandes CM, Zamuner SR, Gutiérrez JM, Teixeira CF. Inflammatory events induced by Lys-49 and Asp- 49 phospholipases A2 isolated from Bothrops asper snake venom: Role of catalytic activity. Toxicon 2005;45:335-46.

10. Kini RM. Excitement ahead: Structure, function and mechanism of snake venom phospholipase A2 enzymes. Toxicon 2003;42:827-40.

11. Perumal Samy R, Gopalakrishnakone P, Bow H, Puspharaj PN, Chow VT. Identification and characterization of a phospholipase A2 from the venom of the Saw-scaled viper: Novel bactericidal and membrane damaging activities. Biochimie 2010;92:1854-66.

12. Thomas ET, Bhagya S, Udayabhaskaran V, Kumar KG, Thulaseedharan NK. Is the concept of "big 4" still relevant in India? Comparison of envenomation by hump-nosed pit viper with russell's viper. Eur J Pharm Med Res 2016;3:306-10.

13. Whitaker R, Whitaker S. Venom, antivenom production and the medically important snakes of India. Curr Sci 2012;103:635-43.

14. Sharma M, Gogoi N, Dhananjaya BL, Menon JC, Doley R. Geographical variation of Indian Russell's viper venom and neutralization of its coagulopathy by polyvalent antivenom. Toxin Rev 2014;3:1-15.

15. Warrell DA. Guidelines for the management of snake-bites [Internet]. World Health Organization Regional Office for South-East Asia; 2010. Available from: http://apps.searo.who.int/PDS_DOCS/B4508.pdf. [Last cited on 2017 Oct 01$]$

16. Thomas RG, Kumar J. Clinical features, prognostic factors \& outcome of capillary leak syndrome in snake bite envenomation. Int J Adv Res 2016;4:2707-10.

17. Kulkarni C, George TA, Av A, Ravindran R. Acute angle closure glaucoma with Capilllary leak syndrome following snake bite. J Clin Diagn Res 2014;8:VC01-3.

18. Srinivasan R, Kaliaperumal S, Dutta TK. Bilateral angle closure glaucoma following snake bite. J Assoc Physicians India 2005;53:46-8.

19. Mohd $\mathrm{H}$, Veena V. Acute angle closure glaucoma: Rare complication of viper bite. KMJ 2008;2:27-8.

20. Rivers E, Nguyen B, Havstad S, Ressler J, Muzzin A, Knoblich B, et al. Early goal-directed therapy in the treatment of severe sepsis and septic shock. N Engl J Med 2001;345:1368-77.

21. ProCESS Investigators, Yealy DM, Kellum JA, Huang DT, Barnato AE, Weissfeld LA, et al. A randomized trial of protocol-based care for early septic shock. N Engl J Med 2014;370:1683-93.
22. ARISE Investigators, ANZICS Clinical Trials Group, Peake SL, Delaney A, Bailey M, Bellomo R, et al. Goal-directed resuscitation for patients with early septic shock. N Engl J Med 2014;371:1496-506.

23. Atkinson JP, Waldmann TA, Stein SF, Gelfand JA, Macdonald WJ, Heck LW, et al. Systemic capillary leak syndrome and monoclonal IgG gammopathy; studies in a sixth patient and a review of the literature. Medicine (Baltimore) 1977;56:225-39.

24. Perner A, Haase N, Guttormsen AB, Tenhunen J, Klemenzson G, Åneman A, et al. Hydroxyethyl starch 130/0.42 versus Ringer's acetate in severe sepsis. N Engl J Med 2012;367:124-34.

25. Brunkhorst FM, Engel C, Bloos F, Meier-Hellmann A, Ragaller M, Weiler $\mathrm{N}$, et al. Intensive insulin therapy and pentastarch resuscitation in severe sepsis. N Engl J Med 2008;358:125-39.

26. Dellinger RP, Levy MM, Carlet JM, Bion J, Parker MM, Jaeschke R, et al. Surviving sepsis Campaign: International guidelines for management of severe sepsis and septic shock: 2008. Crit Care Med 2008;36:296-327.

27. Dellinger RP, Levy MM, Rhodes A, Annane D, Gerlach H, Opal SM, et al. Surviving sepsis Campaign: International guidelines for management of severe sepsis and septic shock: 2012. Crit Care Med 2013;41:580-637.

28. De Backer D, Biston P, Devriendt J, Madl C, Chochrad D, Aldecoa C, et al. Comparison of dopamine and norepinephrine in the treatment of shock. N Engl J Med 2010;362:779-89.

29. Abstracts of the $27^{\text {th }}$ international symposium on intensive care and emergency medicine, Brussels, Belgium, 27-30 March 2007. Crit Care 2007;11 Suppl 2:S1-201.

30. Walsh JT, Hildick-Smith DJ, Newell SA, Lowe MD, Satchithananda DK, Shapiro LM, et al. Comparison of central venous and inferior vena caval pressures. Am J Cardiol 2000;85:518-20, A11.

31. Brennan JM, Ronan A, Goonewardena S, Blair JE, Hammes M, Shah D, et al. Handcarried ultrasound measurement of the inferior vena cava for assessment of intravascular volume status in the outpatient hemodialysis clinic. Clin J Am Soc Nephrol 2006;1:749-53.

32. Mandelbaum A, Ritz E. Vena cava diameter measurement for estimation of dry weight in haemodialysis patients. Nephrol Dial Transplant 1996;11 Suppl 2:24-7.

33. Grace M, Jacob KJ, Jayakumar, Arun P. Secondary capillary leak syndrome - Plasmapheresis: Is it the answer? IAIM 2015;2:187-9.

34. Zengin S, Yilmaz M, Al B, Yildirim C, Yarbil P, Kilic H, et al. Plasma exchange as a complementary approach to snake bite treatment: An academic emergency department's experiences. Transfus Apher Sci 2013;49:494-8.

35. Amoura Z, Papo T, Ninet J, Hatron PY, Guillaumie J, Piette AM, et al. Systemic capillary leak syndrome: Report on 13 patients with special focus on course and treatment. Am J Med 1997;103:514-9.

36. Tahirkheli NK, Greipp PR. Treatment of the systemic capillary leak syndrome with terbutaline and theophylline. A case series. Ann Intern Med 1999;130:905-9.

37. Sultan Y, Kazatchkine MD, Maisonneuve P, Nydegger UE. Anti-idiotypic suppression of autoantibodies to factor VIII (antihaemophilic factor) by high-dose intravenous gammaglobulin. Lancet 1984;2:765-8.

38. Suchithra N, Pappachan JM, Sujathan P. Snakebite envenoming in Kerala, South India: Clinical profile and factors involved in adverse outcomes. Emerg Med J 2008;25:200-4. 